\title{
Individual quality of life in patients with multiple myeloma
}

Julia Dürner ${ }^{1 *}$, Hans Reinecker ${ }^{2}$ and Herbert Csef $^{1}$

\begin{abstract}
Objective: The situation of patients with multiple myeloma, whose treatment often implies high-dose chemotherapy and stem cell transplantation that can be associated with severe symptoms and psychological distress, has gained attention in recent psychooncological research. This study followed an idiographic approach in order to identify the areas of life most relevant for the interviewed myeloma patients' quality of life (QoL) as well as their current satisfaction with these.
\end{abstract}

Methods: 64 patients took part in semi-structured interviews according to the SEIQoL-DW Manual (Schedule for the Evaluation of Individual Quality of Life - Direct Weighting). Visual analogue scales (VAS) were used to gain additional information about a general assessment of the present QoL. Qualitative data evaluation preceded quantitative processing. Groups were compared according to the time elapsed since diagnosis regarding specified areas of life, satisfaction with these and their relative weighting. SEIQoL-DW-indices were correlated to the VAS to reflect on an interindividually comparable parameter.

Results: Personal social relationships were mentioned significantly more often as important for QoL than healthrelated aspects, and in direct comparison were weighted significantly stronger. Regarding the change of areas relevant for QoL over the time elapsed since diagnosis, there was a significant difference between groups concerning the area of spirituality. Satisfaction differed significantly between groups for the field of leisure.

Conclusion: The results for the interviewed patients with multiple myeloma point out the need to take into account the importance of social and individual aspects when reflecting on QoL. Similar findings have been reported for different samples. The relevance of an individualized approach is illustrated by the fact that individually named areas of life were rated comparatively strongly in their importance for the patients' QoL. An overall assessment for the current QoL by means of VAS is regarded as an adequate supplement to the SEIQoL-Profile and an alternative to the SEIQoL-DW-Index.

Keywords: Cancer; Psychooncology; Individual quality of life; Multiple myeloma

\section{Background}

Quality of life has increasingly gained importance as a standard in oncology and is also mentioned in the field of research as a relevant criterion for medical activities (Browne et al. 1997). The conceptualization of 'healthrelated quality of life' has established itself in quality of life research in medical contexts (Bullinger 1997). Respective measures frequently comprise areas of life that are considered as relevant according to the applied

\footnotetext{
* Correspondence: Duerner_J@ukw.de

'Department of Psychosomatic Medicine and Psychotherapy, Clinic of Internal Medicine II, Julius-Maximilians-University of Würzburg, Würzburg, Germany

Full list of author information is available at the end of the article
}

definition or by expert opinion. Content is dominated by items related to health, illness and symptoms, often focusing on health-related quality of life. A prioritization of health-related aspects in the evaluation of quality of life in this context is questioned by the results of research groups who interviewed cancer and ALS (amyotrophic lateral sclerosis) patients on important areas of life for their quality of life (Fegg et al. 2005; Frick et al. 2004; Waldron et al. 1999; Wettergren et al. 2008). The use of standardized questionnaires has been commented on with regards to universality and consistency of relevant areas of life, as well as to implicitly weighting them equally (Browne et al. 1994; Hickey et al. 1999; 
Jenkinson \& McGee 1997). Individualized instruments have shown to reveal areas of life not typically included in standardized instruments but nominated as relevant by the respondents (Waldron et al. 1999; Wettergren et al. 2008). The use of individualized instruments can contribute to gaining a comprehensive picture with special attention to the views of the persons concerned and has been recommended for monitoring patient care (McHorney \& Tarlov 1995; Wettergren et al. 2011; Molassiotis et al. 2011; Hickey et al. 1996). The situation of patients with multiple myeloma, whose treatment often implies high-dose chemotherapy and stem cell transplantation that can be associated with severe symptoms and psychological distress, has gained attention in recent psychooncological research (Frick et al. 2004; Wettergren et al. 2008; Molassiotis et al. 2011).

In the present study, semi-structured interviews were used following an idiographic approach. The objective was to explore the perspective of patients with a specific haematological malignancy and the impact of treatment on the assessment of quality of life by means of identifying areas of life relevant for the interviewed myeloma patients' quality of life, their current satisfaction with these and their relative weighting. Personal social relationships were hypothesized to be most important in the individual assessments of quality of life. The answers of patients during the first year after diagnosis and of patients whose diagnosis dated back more than one year were compared regarding the above-mentioned aspects.

\section{Methods}

\section{Participants and procedure}

The study procedure was previously approved by the Medical Faculty's Ethics Committee of Würzburg University. The data were collected in the Clinic for Internal Medicine II of Würzburg University from May to December 2011. All but six of the approached 70 persons volunteered to take part in an interview. Written informed consent was obtained from all study participants. All interviews were administered by the first author, either in the patient's room, an examination room on the ward, or in an office, according to the participant's preference and physical condition.

\section{Measures}

Data collection followed the SEIQoL-DW Manual (Hickey et al. 1996; O'Boyle et al. 1993). This semistructured interview has been used to evaluate individual quality of life in various samples, e. g. healthy individuals (Browne et al. 1994) as well as patients with congenital heart disease (Moons et al. 2005), stroke survivors (LeVasseur et al. 2005), patients with ALS (LoCoco et al. 2005), and patients with advanced cancer (Waldron et al. 1999). Several research groups have reported data on psychometric properties of the SEIQoL-DW with good results for validity, reliability and sensitivity (Waldron et al. 1999; Patel et al. 2003; Moons et al. 2004; Neudert et al. 2001). During the administration, participants are asked to name the five areas of life currently most important for their quality of life. They then rate their satisfaction with these areas during the last seven days ranging form 0 to 100 . Lastly, the relative importance of each area is determined with a dynamic pie chart which allows to try out different combinations. According to the manual, an index can be calculated by multiplying current satisfaction and relative weighting of each area and summing up the results. Additionally, visual analogue scales were used to gain information about a general assessment of the present quality of life (Moons et al. 2004). The last seven days were defined as a reference period in the instructions for the SEIQoLDW as well as for the visual analogue scales.

\section{Data analyis}

The interview data material was screened and then categorized. Inductive formation of categories followed Mayring's description of the procedure of summarizing qualitative content analysis (Mayring 2008). The category system was reviewed and adapted in a continuous process. The objective was to structure the obtained data for quantitative data processing in order to test hypotheses, but to develop the categories close to the original data so that individually relevant areas for quality of life assessment could be displayed. The categories were defined to comprise mentions of the generic term as well as subordinate terms and their descriptions. To test hypotheses, the named areas of life were further condensed to main categories; e. g. 'family' and 'friends' were both allocated to "personal social relationships". Cohen's Kappa (K) was determined to evaluate category definitions. $15 \%$ of the data were selected at random and were attributed to the categories according to the category system by a person not involved in the study.

McNemar test was used to analyse whether the proportion of participants who had named at least one area of the main category "personal social relationships" was significantly larger than the rate of those who had named at least one aspect of "health" ("personal social relationships" and "health" being the two main categories that most named areas of life were assigned to). To test for differences in the relative weighting of the named areas of life with Wilcoxon signed rank test for paired samples, the data of the 46 participants who had named areas of the main categories both "personal social relationships" and "health" were used. (If a participant had named several areas of life allocated to the same main category, their relative weights were summed up and taken into account for further calculation). 
Table 1 Sample characteristics

\begin{tabular}{|c|c|c|}
\hline & n (\%) & $\begin{array}{l}\text { Median } \\
\text { (range) }\end{array}$ \\
\hline $\begin{array}{l}\text { Total } \\
\end{array}$ & $64(100)$ & \\
\hline Age in years & & $60(33-84)$ \\
\hline \multicolumn{3}{|l|}{ Sex } \\
\hline male & $37(57.8)$ & \\
\hline female & $27(42.2)$ & \\
\hline \multicolumn{3}{|l|}{ Education level } \\
\hline Secondary school & $37(57.8)$ & \\
\hline A-Level/High school degree & $5(7.8)$ & \\
\hline University degree & $22(34.4)$ & \\
\hline \multicolumn{3}{|l|}{ Family status } \\
\hline married & $48(75.0)$ & \\
\hline widowed & $3(4.7)$ & \\
\hline divorced & $8(12.5)$ & \\
\hline single & $5(7.8)$ & \\
\hline \multicolumn{3}{|l|}{ Religious denomination } \\
\hline catholic & $28(43.8)$ & \\
\hline protestant & $25(39.1)$ & \\
\hline none & $11(17.2)$ & \\
\hline \multicolumn{3}{|l|}{ Active faith } \\
\hline yes & $54(84.4)$ & \\
\hline no & $10(15.6)$ & \\
\hline Months since diagnosis & & $15.5(0-147)$ \\
\hline Time of treatment in months & & $11.0(0-147)$ \\
\hline \multicolumn{3}{|l|}{ Current disease status } \\
\hline complete remission & $4(6.2)$ & \\
\hline partial remission & $18(28.1)$ & \\
\hline stable disease & $2(3.1)$ & \\
\hline progressive disease & $8(12.5)$ & \\
\hline recurrence & $2(3.1)$ & \\
\hline beginning of treatment, no information & $8(12.5)$ & \\
\hline $\begin{array}{l}\text { no information during ongoing } \\
\text { treatment }\end{array}$ & $22(34.4)$ & \\
\hline Autologous stem cell transplantation(s) & $33(51.6)$ & \\
\hline Allogenic stem cell transplantation & $8(12.5)$ & \\
\hline
\end{tabular}

Two groups were formed according to the time elapsed since diagnosis (in months) in order to compare the groups' results as to specified areas of life, satisfaction with these and their relative weighting. To test for significant differences, Fisher's exact test and MannWhitney-U-Test were used. SEIQoL-DW-indices were correlated to the visual analogue scalings to reflect on an interindividually comparable parameter. Kendall's Tau correlation coefficient was calculated to test the correlation of SEIQoL-DW-indices and the visual analogue scalings. Findings were considered to be statistically significant for values below $\alpha=0.05$. Statistical tests were performed using the SPSS computer program, version 19.

\section{Results \\ Participants' characteristics}

64 patients with multiple myeloma (27 women and 37 men) volunteered to take part in the study. 30 of them were in their first year of treatment after diagnosis, and 34 at a later point in time in treatment (ranging from 13 to 147 months of treatment). The median age was 60 years (range: 33-84). The participants were mainly inpatients; four of them received outpatient treatment. Further sociodemographic and clinical characteristics of the sample are presented in Table 1. No significant differences were found between the patients in the first year after diagnosis and the patients whose diagnosis dated back more than a year regarding the distribution of the characteristics gender $\left(\mathrm{Chi}^{2}: .03, \mathrm{p}=.862\right)$, age $(\mathrm{t}(62)=-.7, \mathrm{p}=.488)$, family status $\left(\mathrm{Chi}^{2}: 3.8, \mathrm{p}=.862\right)$, educational level $\left(\mathrm{Chi}^{2}: 6.92, \mathrm{p}=.075\right)$, and active faith $\left(\mathrm{Chi}^{2}: 1.36, \mathrm{p}=.244\right)$. The patients received chemotherapeutic treatment, which for $52 \%$ of the sample involved high-dose chemotherapy followed by autologous stem cell transplantation.

\section{Quality of life}

Table 2 presents the main categories formed from the named areas of life most important for the current quality of life and the respective frequencies. The agreement between two raters on the main categories had been evaluated for a randomly selected part of the data at $=.9$. Personal social relationships were named by most participants as important for their quality of life, and they were named significantly more often $(\mathrm{p}=.006$, one-tailed) than health-related or other aspects. Table 3 displays the average relative weights assigned to the main categories. The 46 participants that had named both personal social relationships and health-related aspects as most important for their quality of life had weighted personal social relationships significantly stronger $(\mathrm{p}=.006$, one-tailed) than health-related aspects.

Regarding the difference between groups concerning areas relevant for quality of life of patients in the first year after diagnosis compared to patients whose diagnosis dated back more than a year (Table 4), the number of mentions for the area of spirituality differed significantly ( $p=.027$, two-tailed; Fisher's exact test was conducted for the main categories with the greatest differences in descriptive analysis). Mann-Whitney-U-Test showed a significant difference between groups as to satisfaction with leisure activities $(\mathrm{p}=.028$, two-tailed). Due to the procedure of relative weighting (that opposes statistical independence) no inferential statistical analysis was 
performed. The weights assigned by the groups were only descriptively compared, with the greatest differences for "health", "independence", and "home". "Independence" was in comparison weighted more strongly by participants whose diagnosis dated back more than a year, while the other two aspects were assessed as more important by participants in the first year after diagnosis than by those whose diagnosis dated back more than one year.

The comparison of the values of the SEIQoL-DW-indices and visual analogue scalings showed on average higher values for the calculated indices than for the participants' direct assessments of general quality of life (SEIQoL-DW-index mean: 71.3 and median: 71.5 vs. VAS mean: 57.7 and median: 58.0) with small differences in variability. The two parameters correlate significantly, but at a moderate level $\left(\mathrm{r}=.522^{* *}\right)$.

\section{Individual profiles}

Two examples of SEIQoL-DW-profiles are presented in Figures 1 and 2 to illustrate how differently quality of life can be evaluated at an individual level.

Figures $1 \mathrm{a}$ and $1 \mathrm{~b}$ display the assessment given by a 54-year-old man whose multiple myeloma had been diagnosed eleven months ago. He was in treatment before a first autologous stem cell transplantation. The most important areas of life for quality of life to him were mobility ("that I am able to walk and drive the car"), autonomy ("that I can move around the flat without any help"), health, home, and the contact especially to one person of his family. He reported his view on health to have changed, and that it was much more important to him now than it used to be. He rated his current quality of life in general at 60 of 100 on the VAS, and the calculation of the index added up to 89.3.

Figures $2 \mathrm{a}$ and $2 \mathrm{~b}$ summarize the results of the interview with a 46-year-old woman who had been diagnosed with a smouldering myeloma 77 months ago. At the time of the interview, she was in outpatient treatment after two autologous stem cell transplantations that had been administered after the disease progressed to a stadium that required treatment five years after the diagnosis. The participant described how her way of looking after herself had changed a lot during coping with the disease. She would now pay much more attention to what was good for her. Her job had become less important compared to former times, but she still wished to be able to work again and thus rated work among the most important areas. She assessed her general current quality of life at 86 on the VAS; the value for the index resulted in 95.8 .

\section{Discussion}

The data support the vital importance of personal social relationships and individual aspects for quality of life. The present interpretation does not imply disregarding the relevance of health-related aspects. Rather, the results point out the need to take into account the importance of social and individual aspects when reflecting on quality of life. Similar findings are reported for more heterogeneous samples of patients with different malignancies. The special meaning of social relationships for

Table 2 Description of the main categories and respective frequencies

\begin{tabular}{|c|c|c|c|c|}
\hline Nr. & Main category & Description (including the inductively formed first categories) & $\begin{array}{c}\text { Absolute } \\
\text { frequency }\end{array}$ & Percent $^{\mathrm{a}}$ \\
\hline 1) & $\begin{array}{l}\text { "Personal social } \\
\text { relationships" }\end{array}$ & $\begin{array}{l}\text { Personally relevant social contacts, including the categories 'family', 'spouse', 'children', } \\
\text { 'grandchildren', 'friends' }\end{array}$ & $94^{* *}$ & 29.4 \\
\hline 2) & "Health" & $\begin{array}{l}\text { Terms or descriptions related to physical and psychological state; including the categories } \\
\text { 'absence of pain and other symptoms', 'mobility', 'positive psychological state', 'physical fitness' }\end{array}$ & 69 & 21.6 \\
\hline 3) & "Leisure" & $\begin{array}{l}\text { Leisure activities like "hiking", "hunt"; including the categories 'sport', 'music', 'cultural activities', } \\
\text { 'travelling' }\end{array}$ & 36 & 11.3 \\
\hline 4) & "Independence" & Terms and descriptions for independence/self-determination/autonomy/self-reliance & 19 & 5.9 \\
\hline 5) & $\begin{array}{l}\text { "Financial } \\
\text { situation" }\end{array}$ & $\begin{array}{l}\text { Terms and descriptions regarding the personal financial situation, financial security, financial } \\
\text { independence etc. }\end{array}$ & 17 & 5.3 \\
\hline 6) & "Spirituality" & Terms and descriptions related to faith, religion, religious practice & 17 & 5.3 \\
\hline 7) & "Work" & Also: "job" or descriptions of the professional activity, as well as naming the own business & 16 & 5.0 \\
\hline 8) & "Home" & $\begin{array}{l}\text { Also: "feeling comfortable at home", "my home", descriptions of home and of positive } \\
\text { associations }\end{array}$ & 13 & 4.1 \\
\hline 9) & $\begin{array}{l}\text { "Relation to } \\
\text { nature" }\end{array}$ & $\begin{array}{l}\text { Descriptions of affinity with nature, enjoying closeness to nature, including the category } \\
\text { 'garden' }\end{array}$ & 10 & 3.1 \\
\hline 10) & "Other" & $\begin{array}{l}\text { Once or singularly (less than four times) named areas of life (not matching any of the main } \\
\text { categories) }\end{array}$ & 29 & 9.1 \\
\hline
\end{tabular}

${ }^{a}$ The percentage refers to the total of 320 named areas of life.

** Personal social relationships were named significantly more often ( $p=.006$, one-tailed) than health-related or other aspects. 
Table 3 Average relative weights for the main categories

\begin{tabular}{|c|c|c|c|c|c|}
\hline Rank $^{a}$ & Main category & Mean $^{\mathbf{b}}$ & Median $^{b}$ & Minimum $^{c}$ & Maximum $^{c}$ \\
\hline 1 & "Personal social relationships" & $41.1^{* *}$ & 40.0 & 6.0 & 80.0 \\
\hline 2 & "Health" & 29.3 & 23.5 & 2.5 & 80.0 \\
\hline 3 & "Other" & 22.6 & 17.0 & 5.0 & 32.5 \\
\hline 4 & "Independence" & 21.4 & 17.5 & 5.0 & 75.0 \\
\hline 5 & "Spirituality" & 17.7 & 17.5 & 2.5 & 60.0 \\
\hline 6 & "Home" & 15.8 & 16.7 & 5.0 & 34.0 \\
\hline 7 & "Leisure" & 14.4 & 12.5 & 2.0 & 30.0 \\
\hline 8 & "Work" & 13.5 & 13.5 & 5.0 & 25.0 \\
\hline 9 & "Financial situation" & 13.2 & 10.0 & 5.0 & 44.0 \\
\hline 10 & "Relation to nature" & 10.8 & 10.0 & 3.0 & 20.0 \\
\hline
\end{tabular}

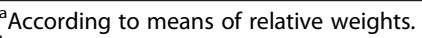

${ }^{b}$ Rounded to one decimal.

${ }^{c}$ Relative weights of singular categories, not sum scores.

** Personal social relationships were weighted significantly stronger ( $p=.006$, one-tailed) than health-related aspects by the 46 participants that had named both personal social relationships and health-related aspects as most important for their quality of life.

quality of life - also in a life situation of severe illness, when health-related aspects have a strong presence and everyday relevance - is underlined by several publications where relationships were the or among the most nominated areas relevant for the quality of life (Fegg et al. 2005; Wettergren et al. 2008; Wettergren et al. 2003; Taminiau-Bloem et al. 2010). These data hint to the limits of quality of life conceptions that focus too strongly on health-related aspects.

Regarding the areas relevant for quality of life, there was a significant difference between groups for the area of spirituality: Respective areas of life were mentioned significantly more often by participants in the first year after diagnosis than by those whose diagnosis dated back more than a year (a Chi ${ }^{2}$-test had shown no significant difference between groups for active faith and other characteristics mentioned above). This can be related to the meaning of religious and spiritual aspects during the coping process and may hint to the interpretation that they are especially important when patients initially adapt to the new situation. Administered in a specific context, repeated measurements with two samples of cancer patients treated with palliative intent reported only small numeric differences in the number of mentions for spiritual aspects between two interviews (Sharpe et al. 2005; Echteld et al. 2005). Wettergren

Table 4 Comparison of group results ${ }^{\mathrm{a}}$

\begin{tabular}{|c|c|c|c|c|c|c|}
\hline \multirow[t]{2}{*}{ Main category } & \multicolumn{3}{|c|}{ Group $1(n=30)$} & \multicolumn{3}{|c|}{ Group $2(n=34)$} \\
\hline & $\begin{array}{c}\text { Patients naming at least } \\
\text { one aspect }\end{array}$ & $\begin{array}{l}\text { Satisfaction } \\
\left(\text { mean }^{\text {b }}\right)\end{array}$ & $\begin{array}{l}\text { Weight } \\
\left(\text { mean }^{\mathrm{b}}\right)\end{array}$ & $\begin{array}{c}\text { Patients naming at least } \\
\text { one aspect }\end{array}$ & $\begin{array}{l}\text { Satisfaction } \\
\left(\text { mean }^{\text {b }}\right)\end{array}$ & $\begin{array}{l}\text { Weight } \\
\left(\text { mean }^{b}\right)\end{array}$ \\
\hline $\begin{array}{l}\text { "Personal social } \\
\text { relationships" }\end{array}$ & $29(96.7 \%)$ & 80.4 & 37.0 & $31(91.2 \%)$ & 79.0 & 45.0 \\
\hline "Health" & $26(86.7 \%)$ & 63.0 & 35.5 & $23(67.6 \%)$ & 62.4 & 22.3 \\
\hline "Leisure" & $11(36.7 \%)$ & 35.0 & 11.2 & $16(47.1 \%)$ & $63.1 * a$ & 16.6 \\
\hline "Independence" & $11(36.7 \%)$ & 57.3 & 16.4 & $8(23.5 \%)$ & 59.4 & 28.3 \\
\hline "Financial situation" & $5(16.7 \%)$ & 64.2 & 12.6 & $12(35.2 \%)$ & 68.6 & 13.4 \\
\hline "Spirituality" & $12(40.0 \%) * b$ & 85.8 & 19.3 & $5(14.7 \%)$ & 53.0 & 13.7 \\
\hline "Work" & $8(26.7 \%)$ & 53.1 & 12.4 & $8(23.5 \%)$ & 57.5 & 14.5 \\
\hline "Home" & $7(23.3 \%)$ & 79.4 & 21.1 & $6(17.6 \%)$ & 80.0 & 9.7 \\
\hline "Relation to nature" & $4(13.3 \%)$ & 66.3 & 10.1 & $6(17.6 \%)$ & 53.3 & 11.3 \\
\hline "Other" & $8(26.7 \%)$ & 64.9 & 21.9 & $13(38.2 \%)$ & 71.9 & 23.8 \\
\hline
\end{tabular}

${ }^{a}$ Group 1: patients during the first year after diagnosis. Group 2: patients whose diagnosis dated back more than a year.

${ }^{b}$ Rounded to one decimal.

${ }^{*}$ Patients whose diagnosis dated back more than a year reported significantly higher satisfaction concerning leisure activities than patients during the first year after diagnosis ( $p=.028$, two-tailed).

${ }^{* \mathrm{~b}}$ Aspects of the main category "spirituality" were mentioned significantly more often by patients in the first year after diagnosis ( $p=.027$, two-tailed). 




et al. found no mentions of spirituality in their administration of the SEIQOL-DW to patients with haematological malignancies before and one year after stem cell transplantation (Wettergren et al. 2008). Gathering more data in longitudinal studies with repeated measurements in could help to clarify the role of spiritual coping, changes regarding the concept of health and other response shift processes in different stages of coping with cancer. The result of a significant difference as to satisfaction with the field of leisure can point to actual changes in recreational activities or to response shift. It is an outstanding feature of individualized measures like the SEIQoL-DW that response shift processes can be captured directly in repeated measurements.

The significance of an individualized approach is illustrated by the fact that individually named areas of life, e. g. "my pet", "sleep", "nutrition", "self-care", were rated comparatively strongly in their importance for the individual quality of life (compare Table 3). The moderate correlation between the visual analogue scaling assessments and the calculated indices illustrates the assumption that different aspects are captured by both measures; and there is obviously a difference between asking for the status and weighting of the most important areas of quality of life and asking for an overall assessment of quality of life. On average higher scores for the SEIQoL-DW-Index compared to the assessments on visual analogue scales are also reported by Frick et al. (Frick et al. 2004) and Pearcy et al. (Pearcy et al. 2008).
The visual analogue scaling may be influenced by factors that are not represented in the determination of the Index. Since the majority of participants in our study were inpatients, aspects of the present situation such as treatment side effects, absence from home etc. may have affected their global quality of life-assessment in the visual analogue scales to a greater extent than their evaluation of the most important areas in the SEIQoL-DW. The SEIQoL-DW authors ask for careful interpretations of the Index and its interindividual comparability (Jenkinson \& McGee 1997; O'Boyle et al. 1993), and the original SEIQoL Manual included a visual analogue assessment. An overall assessment for the current quality of life by means of visual analogue scales is regarded as an adequate supplement to the SEIQoL-Profile and an alternative to the SEIQoL-DW-Index. Rather than reducing quality of life assessments to an interindividually comparable parameter (be it the Index or via VAS), the areas of life named by the participants, satisfaction with these und their weighting should be considered when comparing assessments.

The procedure of administering the SEIQoL-DW interview was described inconsistently by different authors, asking participants either to rate their current satisfaction with the areas or the current status of functioning of the areas, and thus highlighting rather subjective or objective aspects (Wettergren et al. 2009). In this study, we decided to focus on the more subjective aspect of satisfaction considering the special relevance of
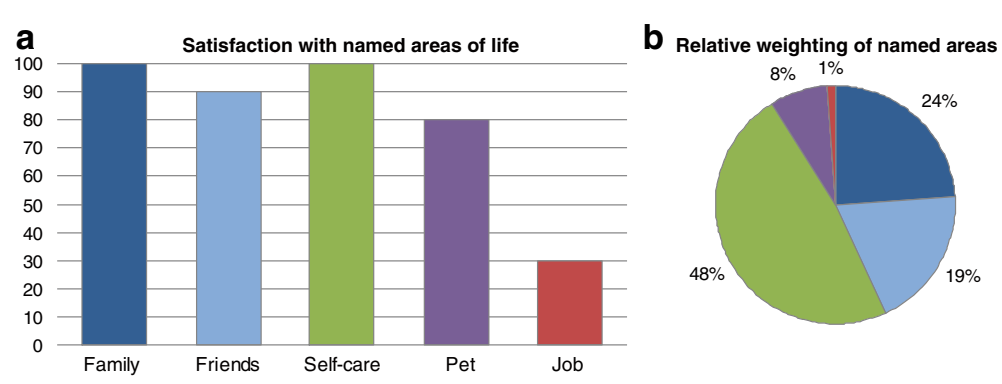

Figures 2 a and b SEIQoL-DW-Profile of a 46-year old woman 77 months after diagnosis. 
subjective evaluations compared to objective factors for quality of life assessments (Waldron et al. 1999; Moons et al. 2004; Herschbach 2002). The manual instruction regarding the relative weighting of the areas was extended by one sentence labelling equal and different weights for the named areas as equivalent options in order to avoid biases.

The SEIQoL-DW-Manual's instruction to ask for the five areas of life most important to the current quality of life is a limitation to the present study. This regulation was not changed when planning the study for reasons of adherence and comparability. Nevertheless, objections regarding the independence of the named areas and their weighting were considered during data analysis. The SMiLE (Schedule for Meaning in Life Evaluation) is an analogously designed measure, whose authors decided in the course of their studies to abandon asking for a fixed number of areas of life (Fegg et al. 2010) (this instruction had been introduced in the SEIQoL-Manual for methodological reasons that expired with the development of the SEIQoL-DW-Disc). In terms of consequently realising an idiographic approach, dropping this requirement should be considered for future applications of the SEIQoL-DW as well. That would also make the potentially problematic procedure of presenting a prompt list to participants who name less than five areas of life dispensable (Westerman et al. 2006). (In the present study, this was relevant for less than $4 \%$ of the data).

Setting effects must be kept in mind as most of the interviews were conducted during inpatient treatment. This context may particularly trigger feelings of fear and helplessness that can influence the reflection on and assessment of quality of life. During some of the interviews held in the patient's room there were other persons present (11 interviews, i. e. 7\%), e. g. other patients when both patients were limited in their mobility and the participant declared not to be disturbed by the presence of the other patient or visiting relative. This implies that social desirability effects cannot be excluded, also because the interviews were administered by a staff member of the hospital (not involved in patient care for the interviewed patients).

\section{Conclusion}

The medical treatment of haematological malignancies is continually improving, and the impact on quality of life is of growing interest, especially in the context of intensive treatments such as stem cell transplantations (Montgomery et al. 2002). This study focused on an idiographic approach to explore and describe relevant areas of life for the quality of life of patients with multiple myeloma. The results underline how important it is in the clinical context to ask patients which aspects they rate most important for their quality of life, e. g. in the context of treatment related decisions. Depending on the objective, standardized and individualized measures can be regarded as complementing each other (Wettergren et al. 2008). Repeated measurements with measures that take into account not only health-related, but also social and individual aspects can provide a different perspective on the experiences of the persons concerned and can help to better understand relevant factors for quality of life in the course of treatment (Osbourne et al. 2012).

\section{Competing interests}

The authors report no conflicts of interest. The authors have full control of all primary data.

\section{Authors' contributions}

JD and HC developed the study design. The study was supervised by HR. JD carried out data collection, performed statistical analysis, and drafted the manuscript. HR and HC contributed to the preparation of the manuscript. All authors read and approved the final manuscript.

\section{Acknowledgements}

We would like to thank all the men and women who consented to communicate an individual evaluation of their quality of life. We thank Dipl.Math. Sabine Karl und Dr. Miriam Kunz for their advice on statistical analyis.

\section{Author details}

'Department of Psychosomatic Medicine and Psychotherapy, Clinic of Internal Medicine II, Julius-Maximilians-University of Würzburg, Würzburg, Germany. ${ }^{2}$ Department of Clinical Psychology and Psychotherapy, Otto-Friedrich-University of Bamberg, Bamberg, Germany.

Received: 8 July 2013 Accepted: 27 July 2013

Published: 23 August 2013

\section{References}

Browne JP, O'Boyle CA, McGee HM, Joyce CRB, McDonald NJ, O'Malley K, Hiltbrunner B (1994) Individual quality of life in the healthy elderly. Qual Life Res 3:253-44

Browne JP, McGee H, O'Boyle CA (1997) Conceptual approaches to the assessment of quality of life. Psychological Health 12:737-751

Bullinger M (1997) Health related quality of life and subjective health. Psychother Psych Med 47:76-91

Echteld MA, Deliens L, Ooms ME, Ribbe M, van der Wal G (2005) Quality of life change and response shift in patients admitted to palliative care units: a pilot study. Palliat Med 19:381-388

Fegg MJ, Wasner M, Neudert C, Borasio GD (2005) Personal values and individual quality of life in palliative care patients. J Pain Symptom Manage 30:154-159

Fegg MJ, Brandstätter M, Kramer M, Kögler M, Haarmann-Doetkotte S, Borasio GD (2010) Meaning in life in palliative care patients. J Pain Symptom Manage 40:502-509

Frick E, Borasio GD, Zehentner H, Fischer N, Bumeder I (2004) Individual quality of life of patients undergoing autologous peripheral blood stem cell transplantation. Psychooncology 13:116-124

Herschbach P (2002) The "Well-Being Paradox" in Quality-of-Life-Research - On what does our sense of well-being depend? Psychother, Psych, Med 52:141-150

Hickey AM, Bury G, O'Boyle CA, Bradley F, O'Kelly FD, Shannon W (1996) A new shortform individual quality of life measure (SEIQoL-DW): application in a cohort of individuals with HIV/AIDS. Br Med J 313:29-33

Hickey A, O'Boyle CA, McGee H, Joyce CRB (1999) The schedule for the evaluation of individual quality of life. In: Joyce CRB, O'Boyle CA, McGee H (eds) Individual quality of life: approaches to conceptualisation and assessment. Harwood academic publishers, Amsterdam, pp 119-133

Jenkinson C, McGee HM (1997) Patient assessed outcomes: measuring health status and quality of life. In: Jenkinson C (ed) Assessment and evaluation of health and medical care. Open University Press, Buckingham, pp 64-84 
LeVasseur SA, Green S, Talman P (2005) The SElQoL-DW is a valid method for measuring individual quality of life in stroke survivors attending a secondary prevention clinic. Qual Life Res 14:779-788

LoCoco G, LoCoco D, Cicero V, Oliveri A, LoVerso G, Piccoli F, LaBella V (2005) Individual and health related quality of life assessment in amyotrophic lateral sclerosis patients and their caregivers. J Neurol Sci 238:11-17

Mayring P (2008) Qualitative Inhaltsanalyse, 10th edn. Weinheim, Beltz

McHorney CA, Tarlov AR (1995) Individual-patient monitoring in clinical practice: are available health status surveys adequate? Qual Life Res 4:293-307

Molassiotis A, Wilson B, Blair S, Howe T, Cavet J (2011) Unmet supportive care needs, psychological well-being and quality of life in patients living with multiple myeloma and their partners. Psychooncology 20:88-97

Montgomery C, Pocock M, Titley K, Lloyd K (2002) Individual quality of life in patients with leukaemia and lymphoma. Psychooncology 11:239-243

Moons P, Marquet K, Budts W, De Geest S (2004) Validity, reliability and responsiveness of the schedule for the evaluation of individual quality of life - direct weighting (SEIQoL-DW) in congenital heart disease. Health Qual Life Outcomes 2

Moons P, Van Deyk K, De Geest S, Gewillig M, Budts W (2005) Is the severity of congenital heart disease associated with the quality of life and perceived health of adult patients? Heart 91:1193-1198

Neudert C, Wasner M, Borasio GD (2001) Patients' assessment of quality of life instruments: a randomised study of SIP, SF-36 and SEIQOL-DW in patients with amyotrophic lateral sclerosis. J Neurol Sci 191:103-109

O'Boyle CA, Browne J, Hickey A, McGee H, Joyce CRB (1993) Manual for the SEIQoL-DW. Department of Psychology. Royal College of Surgeons in Ireland, Dublin

Osbourne TR, Ramsenthaler C, Siegert RJ, Edmonds PM, Schey SA, Higginson IJ (2012) What issues matter most to people with multiple myeloma and how well are we measuring them? a systematic review of quality of life tools. Eur J Haematol 89:437-457

Patel KK, Veenstra DL, Patrick DL (2003) A review of selected patient-generated outcome measures and their application in clinical trials. Value Health 6:595-603

Pearcy R, Waldron D, O'Boyle C, MacDonagh R (2008) Proxy assessment of quality of life in patients with prostate cancer: how accurate are partners and urologists? J R Soc Med 101:133-138

Sharpe L, Butow P, Smith C, McConnell D, Clarke S (2005) Changes in quality of life in patients with advanced cancer: evidence of response shift and response restriction. J Psychosom Res 58:497-504

Taminiau-Bloem EF, Visser MRM, Tishelmann C, Koeneman MA, van Zuuren FJ, Sprangers MAG (2010) Somatically ill persons' self-nominated quality of life domains: review of the literature and guidelines for future studies. Qual Life Res 19:253-291

Waldron D, O'Boyle CA, Kearney M, Moriarty M, Carney D (1999) Quality of lifemeasurement in advanced cancer: assessing the individual. J Clin Oncol 17:3603-3611

Westerman M, Hak T, The AM, Groen H, van der Wal G (2006) Problems eliciting cues in SEIQoL-DW: quality of life areas in small-cell lung cancer patients. Qual Life Res 15:441-449

Wettergren L, Björkholm M, Axdorph U, Bowling A, Langius-Eklöf A (2003) Individual quality of life in long-term survivors of Hodgkin's lymphoma - a comparative study. Qual Life Res 12:545-554

Wettergren L, Sprangers M, Björkholm M, Langius-Eklöf A (2008) Quality of life before and one year following stem cell transplantation using an individualized and a standardized instrument. Psychooncology 17:338-346

Wettergren L, Kettis-Lindblad Å, Sprangers M, Ring L (2009) The use, feasibility and psychometric properties of an individualized quality-of-life instrument: a systematic review of the SEIQoL-DW. Qual Life Res 18:737-746

Wettergren L, Lindblad AK, Glimelius B, Ring L (2011) Comparing two versions of the schedule for evaluation of individual quality of life in patients with advanced cancer. Acta Oncol 50:648-652

doi:10.1186/2193-1801-2-397

Cite this article as: Dürner et al:: Individual quality of life in patients with multiple myeloma. SpringerPlus 2013 2:397.

\section{Submit your manuscript to a SpringerOpen ${ }^{\odot}$ journal and benefit from:}

- Convenient online submission

- Rigorous peer review

- Immediate publication on acceptance

- Open access: articles freely available online

- High visibility within the field

- Retaining the copyright to your article

Submit your next manuscript at $\gg$ springeropen.com 